\title{
Bilateral (acute) hydronephrosis mimicking polycystic renal pathology
}

\begin{abstract}
Complete or partial urethral obstruction results in progressive nephropathy in the subsequent calyxal and renal parenchymal damage. We report a case controlled giant hydronephrosis mimicking multiple polycystic kidney disease (PCKD). The fluid content in the collecting duct is about 1.4liters.

A 40years old man with renal dimensions measuring RK: 118x62mm; LK: 120x65mm respectively reported for ultrasound examination. There was no evidence of malignancy after 8-month follow-up ultrasonography with drug treatment in the internal medical unit; plus urologic evaluation and documentation. Expelled urinary volume via catheter was consistently measured.

Although clinical symptoms and alternate list of diagnosis were suspected, it turned out to be a case of large hydronephrosis. Accurate diagnosis became challenging due to distortion of renal parenchyma and calyxal atrophy. Examining clinical presentations, real-time sonogram evaluation and treatment medication, it is concluded that ureteric calculus may be a main cause of bilateral hydronephrosis.
\end{abstract}

Keywords: hydronephrosis, cysts, ultrasound, catheter
Volume 4 Issue 4 - 2017

\author{
Afodun Adam Moyosore, ${ }^{1,2}$ Bakare Airat \\ Adeola, ${ }^{3}$ Eze Ejike Daniel, ${ }^{4}$ Quadri Khadijah \\ Kofoworola, ${ }^{5}$ Lawal Sodiq Kolawole,' Buhari \\ Muhammad Olanrewaju' \\ 'Department of Anatomy, Kampala International University, \\ Uganda \\ ${ }^{2}$ Department of Radiology, Crystal Specialist Hospital, Nigeria \\ ${ }^{3}$ Department of Anatomy, University of Lagos, Nigeria \\ ${ }^{4}$ Department of Physiology, Kampala International University, \\ Uganda \\ ${ }^{5}$ Department of Physiology, University of llorin, Nigeria
}

Correspondence: Afodun Adam Moyosore, Department of Anatomy, Faculty of Biomedical Science, Kampala International University, Uganda, Department of Radiology, Ultrasound and Doppler Unit, Crystal Specialist Hospital,Akowonjo-Dopemu, Lagos, Nigeria, Tel +2348077295769, +256754792056, Email afodunadam@yahoo.com

Received:September 07, 2017 | Published: November 13, 2017

\section{Introduction}

According to Mergener et al. ${ }^{1}$ Benign Prostatic Hypertrophy (BPH) accounts for increased incidence of hydronephrosis in males, while it is likely due to cyesis or endometriosis in females. Hydronephrosis refers to dilation in the calyx and renal pelvis near region of constriction in the urinogenital tract. This may or may not be associated with abnormal pyramidal pathology as the site of obstruction to urine passage indicates bilateral or unilateral hydronephrosis. ${ }^{2}$

Occurrence of giant hydronephrosis is rare and usually contains about 1.8litres of fluid in the ductules. Polyuria associated with hydronephrosis seems correctable through interactional (and nonsurgical) means. It is well documented that ${ }^{3}$ the practice of nonsurgical management/reduction of Pelvi-Ureteric Junctional (PUJ) obstruction may potentially reducing the number of premature renal uropathies.

In 2004, Lewis et al. ${ }^{4}$ concluded that retrospective Ball on dilation is an effective treatment method for PUJ obstruction with long term alleviating effect. The adverse effect of an aquaretic drug (polyuria, nausea and thirst) will interrupt the lifestyle of some patients. However, subjects at risks of rapid progressive hydronephrosis might prefer treatment with an aquaretic-drug and endure its side effects. Drugs capable of interfering with water hemostasis should be avoided as should anticholinergic medications with known undesired ability to limit bladder contractability. ${ }^{5}$

From literature, 2 in 10 patients undergoing dialysis have polycystic kidney disease (PCKD), with increased renal hypertrophy by a factor of 4.3 with partially impaired kidney function.
Though a common occurrence, complete or partial urethral obstruction produces a progressive damaging (reverse) renal pathology in the excretory kidney function. Multiple foci/stones or calculi may form if proliferation or infection occurs with subsequent impaired urination and kidney parenchymal destruction. ${ }^{6,7}$

\section{Case report}

This clinical observation was made at the Department of Radiology, Crystal Specialist Hospital (CSH) Akowonjo-Lagos, Nigeria. A male patient with hydronephrosis related (but not limited) to PUJ obstruction, stricture of the ureter negated (oral history) of symptoms like weight gain or loss, fever, increased temperature and fatigue.

Sonographic confirmation of hypertrophied but 'polar' kidneys; similar to embedded renal cysts with predominantly low echogenicity and multiple sonopenic fluid spaces (Figure 1) (Figure 2). A General Electric (GE) Pro-Logic 3 ultrasound machine (made in the USA) with a $3.5 \mathrm{MHz}$ curvilinear transducer was used for scanning. There was no sonic evidence of malignant disease. Informed consent of patient was obtained and ethical approval was granted by CSH in line with the 1975 reviewed Helsinki Declaration on confidentiality and patientrights. Prior to the diagnosis of hydronephrosis, fasting for 6hours and dehydration test was made. Recent history review through oral discussion with patient and medical case-note revealed compulsive and excessive water intake about 5years ago (Table 1).

By July 2016 (see sonograms), no reflux in patient was observed post-micturition cystography. At present, December 2016, after follow-up presentation for ultrasound, increased urination averaging 
29 times/day, with stable kidney function; serum creatinine: $1.48 \mathrm{mg}$ $\delta 1$. Though some patients have undergone surgical procedure to alleviate functional obstruction, ${ }^{8}$ it is advisable treatment is medical Instruction to patients on the importance of early frequent voiding cannot be overemphasized. The RT kidney (Figure 1) measured $118 \times 62 \mathrm{~mm}$ in longitudinal and AP diameters, LT kidney (Figure 3) (Figure 4) dimension was $120 \times 65 \mathrm{~mm}$ before progression.

Table I Gauged urine quantity (via in-situ Foley's Catheter)

\begin{tabular}{lll}
\hline Nocturnal urination & $\begin{array}{l}\text { Daytime } \\
\text { micturition }\end{array}$ & $\begin{array}{l}\text { Total daily } \\
\text { diuresis }\end{array}$ \\
\hline $1895 \pm 163 \mathrm{ml}$ & $6138 \pm 349 \mathrm{ml}$ & $8168 \pm 257 \mathrm{ml}$ \\
$2576 \pm 402 \mathrm{ml}$ & $2500 \pm 630 \mathrm{ml}$ & $471 \pm 125 \mathrm{ml}$ \\
\hline
\end{tabular}

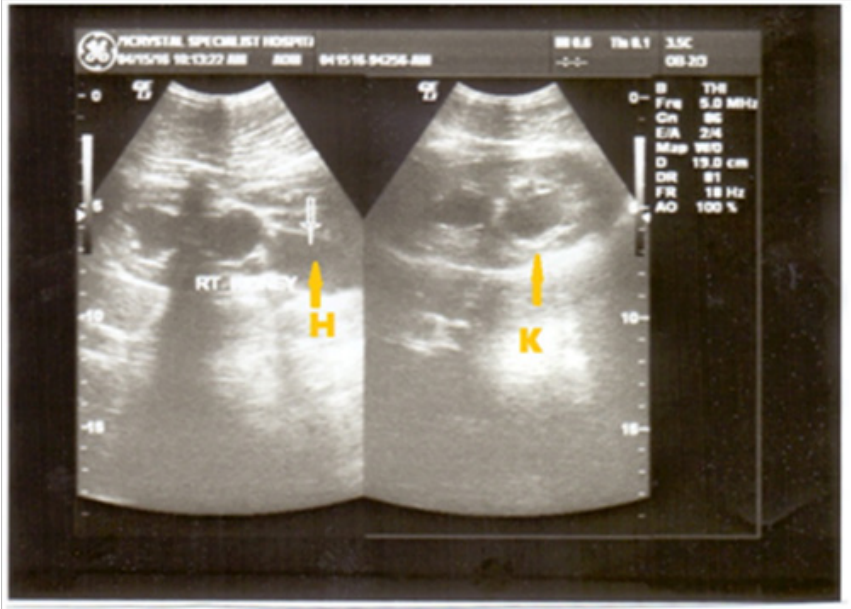

Figure I Acute hydronephrosis of the RT kidney (K) with cystic-like corticomedullary differentiation, note isolated dilation of the renal pelvis.

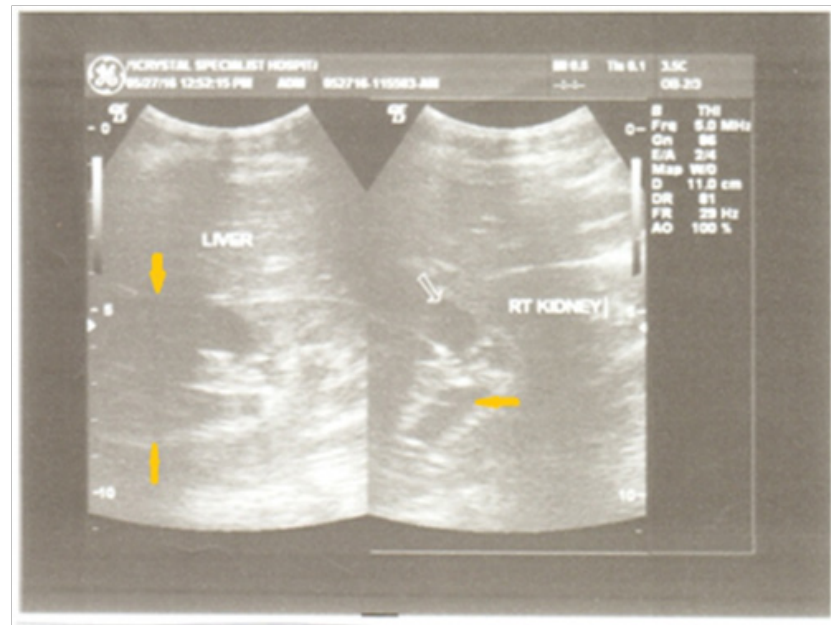

Figure 2 (Ultrasound B-mode split image) RT kidney with possibility of refluxing primary mega-ureter. Progressive renal failure can occur even after treatment due to abnormal physiologic bladder function. Note the arrow pointed downwards.

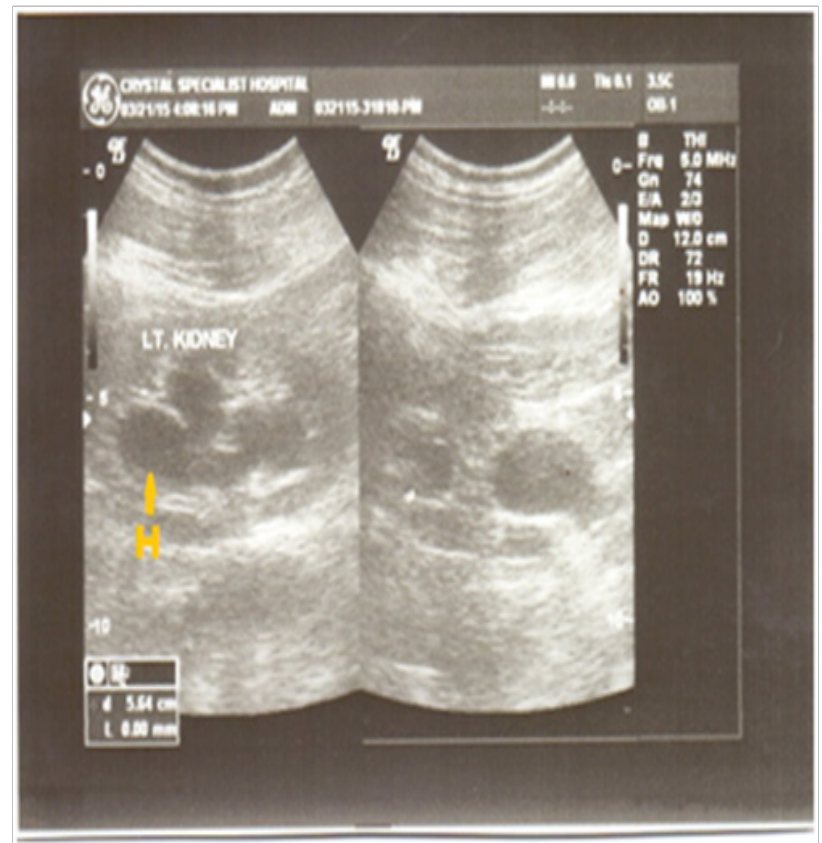

Figure 3 LT renal bulge with AP diameter of $65 \mathrm{~mm}$, observe severe dilation of the lower pole overlying cortical thinning (see arrow) and minor calyces. The patient laid in both supine and decubitus positions. Observe the hydronephrotic $(\mathrm{H})$ accumulation.

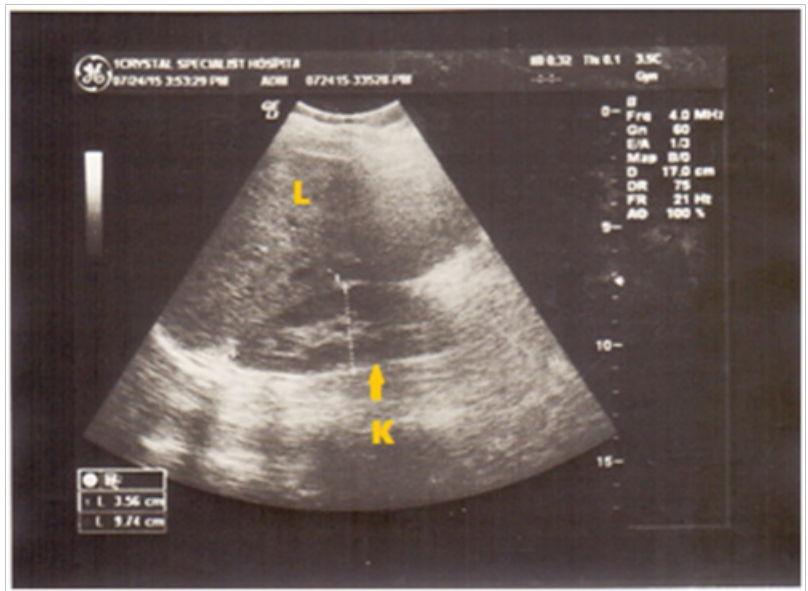

Figure 4 Normal liver (L) and RT kidney (K), the hepato-renal angle (Morissons' pouch) is within anatomical limits.

\section{Discussion}

Hydronephrosis caused by PUJ impairment formed approximately $38 \%$ of our previous study before this case report. Most of the patients who earlier came with symptoms to (CSH) were in the late teen-age group. On physical palpation subjects had tenderness and resistance in the lumber region, accounting for $88 \%$ of patients. A study ${ }^{9}$ in 2001 carried out pyeloplasty in 56 cases over a decade and concluded that the procedure is an excellent innovation for PUJ obstruction and produces clear urinary tract drainage. Although ill patients have undergone surgical procedure to alleviate functional tract obstruction ${ }^{8}$ we suggest treatment is made medical. Multiple dilated calyces (Figure 1), loss of corticomedullary differentiation, renal dysplasia 
and increased parenchymal echogenicity are all anatomical landmarks in-situ of the diseased kidneys.

Social inconvenience of frequent voiding e.g. in an airplane, makes sufferers adopt self-urinary retention which further exacerbate chronologic uropathy in line with the findings of Boyd et al. ${ }^{10}$ Furthermore, cases of moderate (non-acute) dilation may resolve with time. In severe persistent hydronephrotic kidneys, a long-term sonar follow-up is required because of the possibility of late worsening. It (hydronephrosis) can be further graded into severe, mild or moderate according to AP diameter of the kidneys based on observed sonogram pathology. Time frame for recurrence can vary from a few months to within a 3year period.

Improved medication after a short period of time can lead to marked improvement in kidney tract dilation, if diagnosis by ultrasound is made early. Chronic renal failure rarely occurs ${ }^{11}$ however, persistent hydronephrosis presumably of many years can be improved and managed in line with the assertion of Tank et al., ${ }^{12}$ Singer et al., ${ }^{13}$ followed up stented patients; concluding medical management is of great value in the early detection of morbidity and other complications of hydronephrosis. Prolonged and sustained polyuria (diuresis $>30 /$ day) is usually a cause of reduced tubular fluid resorption and obstructed uropathy in some patients. This is similar to an earlier literature reporting by Drach. ${ }^{6}$ Multiple dilated calyces and loss of corticomedullary differentiation (Figure 1) and partial increased parenchymal echogenicity are all anatomical landmarks insitu of the diseased kidneys.

Physical impairment to urine flow results in the disruption of glomerular hemodynamics and tubular function, caused by a variety of vasoactive factors. However; hematuria, resistance in the lumbar area (on palpation), low abdominal pain and urgency in urination are associated symptoms. Endoscopy combined with pressure-releasing surgical procedure should be used in managing nephrological interventions. In severe cases, thickness of renal parenchyma should be determined during scanning.

Treatment drugs with aquaretic side effects (polydipsia, polyuria, nocturia and thirst) were associated with increased level of uric acid and gout. Compared with patients who received placebo, the rate of increase in kidney volume was low in both study groups $(2.8 \%$ per year in toluaptan and $5.5 \%$ per year in placebo) contrasting to $10 \%$ per year in other studies. ${ }^{14-16}$ If abnormal bladder function combine with acute hydronephrosis progressive renal failure may occur.

\section{Conclusion}

There are obvious limitations in viewing renal vasculature (of hydronephrotic kidneys) with grey scale ultrasound in this case report. Color Doppler evaluation will further differentiate between non-obstructive and obstructive hydronephrosis. Renal-foci, streaks of calcification and ureteric calculus can be a cause of hydronephrosis when seen.

\section{Acknowledgements}

None.

\section{Conflicts of interest}

Non-declared, the case note is self-sponsored.

\section{References}

1. Mergener K, Wein Erth JL, Baille T. Dietl's crisis: A syndrome of episodic abdominal pain of urologic origin that may present to a gastroenterologist. Am J Gastroenterol. 1997;92(21):2289-2291.

2. Walsh PC. Pathophysiology of urinary obstruction In: Walsh, editor. Campbell's Urology. 8th ed. Philadelphia: WB Saunders; 2002. p. 412-440.

3. Pinter AB, Horwath A, Hraborsky Z. The relationship of smooth muscle damage to age, severity of pre-operative outcome in obstructive uropathies. Br J Urol. 1997;80(2):227-233.

4. Lewis JM, Natale RS, Hammonds JC, et al. Records of 58 adult patients who had undergone retrograde ballon dilation of pelvis matric/miction obstruction during a ten year period were studied. British Journal of Urology International. 2004;93:360-363.

5. Singh H, Linas SL. Compulsive water drinking in the setting of anticholinergic drug use: An unrecognised cause of chronic renal failure. Am J Kid Dis. 1995;26(4):586-589.

6. Drach GW. Urinary lithiasis. In: Walsh, editor. Campbell's Urology. 5th ed. Philadelphia: WB Saunders; 1986. p. 1124-1125.

7. Gupta RL. The kidneys and ureters. In: Jaypee Brothers, editor. Textbook of surgery. 2nd ed. New Delhi, India; 2003. p. 1031-1057.

8. Nakada T, Miyauchi T, Sumiya H, et al. Nonobstructive urinary tract dilatation in nephrogenic diabetes insipidus. Int Urol Nephrol. 1990;22(5):419-427.

9. O'Reilly PH, Broomau PCJ, Maks S, et al. Studied the long term results of Anderson-Hynes pyeloplasty. BJU Int. 2001;87(4):287-290.

10. Boyd SD, Eaz S, Ehrlich RM. Diabetes insipidus and nonobstructive dilatation of urinary tract. Urology. 1980;16(3):266-269.

11. Streitz JM Jr, Streitz JM. Polyuric urinary tract dilatation with renal damage. J Urol. 1988;139(4):784-785.

12. Tank ES, Alexander SR, Craven RM. Polyuric megalocystitis. $J$ Urol. 1980;124(5):692-694.

13. Singer I, Oster JR, Fishman LM. The management of diabetes insipidus in adults. Arch Intern Med. 1997;157(12):1293-1301.

14. Serra AL, Poster D, Kristler AD, et al. Sirolimus and kidney growth in autosomal dominant polycystic kidney disease. $N$ Engl $J$ Med. 2010;363(9):820-829.

15. Ruggenenti P, Remuzzi A, Ondei P, et al. Safety and efficacy of long acting somatostatin treatment in autosomal dominant polycystic kidney disease. Kidney Int. 2005;68(1):206-216.

16. Korzets A, Sachs D, Gremitsky A, et al. Unexplained polyuria and non-obstructive hydronephrosis in a urological department. Nephrol Dial Transplant. 2004;19(9):2410-2412. 